\title{
Histopathological and Histochemical Assessment of Monosodium Glutamate-Induced Hepatic Toxicity and the Amelioration with Propolis.
}

\author{
Mahrous A. Ibrahim ${ }^{1,2}$, Athar M. Khalifa ${ }^{3}$, Amro A. Saleh ${ }^{4}$ and Hany G. Tammam ${ }^{5}$ \\ ${ }^{1}$ Forensic Medicine and Clinical Toxicology, College of Medicine, Jouf University, Sakaka, Saudi Arabia. \\ ${ }^{2}$ Forensic Medicine and Clinical Toxicology Department, Faculty of Medicine, Suez Canal University, Ismailia, Egypt. \\ ${ }^{3}$ Pathology Department, College of Medicine, Jouf University, Sakaka, Saudi Arabia \\ ${ }^{4}$ Forensic Medicine and Clinical Toxicology Department, Faculty of Medicine, Fayoum University, Egypt. \\ ${ }^{5}$ Forensic Medicine and Clinical Toxicology Department, Faculty of Medicine, Alazhar University, Egypt.
}

\begin{abstract}
Introduction: Monosodium glutamate (MSG) is utilized to enhance appetite and there is rising solicitude that MSG has a role in the evolution of hepatic disturbances. Propolis has been notified to have a considerable role in the amelioration of hepatic toxicity. Aim: The aim of this study is to investigate the protective effect of propolis on hepatotoxicity induced by MSG. Materials and methods: Forty-eight male rats were divided into four equal groups (Gp). GpI was served as a control, GpII was treated orally with propolis (90mg/kg bw) and GpIII was treated with MSG ( $97 \mathrm{mg} / \mathrm{kg} \mathrm{bw}$ ). GpIV was treated with MSG and propolis in the same doses as GpII and GpIII. All agents were administrated orally once daily for 6 weeks. Then, rats were sacrificed and blood samples were collected for biochemical analysis. Liver tissues were harvested for histopathological and histochemical examinations with determination of oxidative markers. Results: The results showed that the levels of ALT, AST, and ALP significantly augmented in MSG-treated rats whereas serum albumin level significantly declined. Rats' exposure to MSG increased oxidative parameters; malondialdehyde (MDA) in the tissue, in parallel with decreased antioxidant enzymes levels as well as histopathological damages in the hepatic tissue. The administration of propolis highly mitigated the hepatotoxic influences of MSG based on biochemical and histological alterations. Conclusion: In summary, the study obviously indicates that MSG-induced hepatic toxicity could be protected by propolis administration and such beneficial properties could be attributed to the polyphenolic compounds present in these natural products.
\end{abstract}

Key words Histopathology; Monosodium glutamate; Propolis; Hepatotoxicity; Oxidative stress

\section{Introduction}

The metabolism of xenobiotic largely takes place in the liver. The by-product of such metabolism sometimes becomes more toxic than the parent substance. This could lead to liver injury and the emergence of hepatic diseases. These by-products include oxygen- containing molecules that damage vital cell components through oxidation. The liver contains a considerable amount of polyunsaturated fatty acids that are prone to damage by free radicals through oxidative stress (Onyema et al., 2006).

Eating manner has a fundamental role in metabolic and food-related diseases. Lately, the modern high tech diet contains abundant of chemicals compounds. Monosodium glutamate (MSG)- 1-glutamic acid- is widely used to preserve foods and to enhance its palatability, with its sodium salt, which naturally present making its toxicity a significant area of animal and human research (Dixit et al., 2014).

MSG is one of the ultimate numerous naturally present non-essential amino acids and the treatment with MSG could have the ability to induce metabolic alterations, which can enhance the development of severe body disorders (Eweka and Om'Iniabohs, 2011). The components of MSG include sodium and water (22\%) and glutamic acid (78 \%). Glutamate as a main component in MSG is one of the major ingredient of numerous peptides and proteins and it is extremely widespread amino acids in the nature. Furthermore, the amino acid Glutamate is generated in the human body and has a vital role in the metabolism of the systems of human body. Monosodium 1-glutamate (MSG), chemically known as 2-amino pentane dioic or 2-amino 
glutamic. MSG is excessively added to the food to enhance its flavor and in many conditions; its name is not mentioned on the label of the food packages. The identification of this foods additive (MSG) was done after its laboratory isolation in the previous years. New MSG was produced for commercial purposes by fermentation of molasses, beet sugarcane, sugar, or starch (Hamza and Al-Harbi, 2014).

Some studies specified that Monosodium glutamate has toxic effects on the human body and animals in labs (Al-Harbi et al., 2014). Many symptoms could be induced by MSG such as flushing, weakness, sweating, numbness, headaches and dizziness. Furthermore, considerable disorders could be attributed to MSG ingestion, including atopic dermatitis, abdominal discomfort, asthma, ventricular arrhythmia and neuropathy (Torii, 2012).

Antioxidants have been reported to play a significant role in the protection against lipid peroxidation. Some researchers have shown that oxidative stress hepatic damage induced by MSG exposure are protected by antioxidants agents cotreatment and free radical scavengers (Onyema et al., 2006, Farombi and Onyema, 2006).

Propolis (PP) is a sticky substance which is gathered and utilized by honeybees (Rizk et al., 2014). It has been utilized in people prescription everywhere throughout the world. It plays many roles as immunoregulatory, anti-inflammatory, anticancer, antibacterial, antioxidant and bacteriostatic efficiencies (Bueno-Silva et al., 2013). It likewise has a potent cytoprotective impact against various exogenous harmful and toxic agents (Rizk et al., 2014). The aim of this study was to investigate the possible effect of propolis in ameliorating MSG induced-hepatotoxicity in rats.

\section{Material and methods}

\section{Animals}

Forty-eight adult male albino rats, of almost the same age $(\sim 1$ month $)$ and weighted $(187.68 \pm 8.26)$ were purchased from the animal house colony of the national research center (NRC, Giza, Egypt). Rats were allowed one-week acclimatization period and were housed in groups in standard plastic cages at constant temperature $\left(23 \pm 2{ }^{\circ} \mathrm{C}\right)$, humidity $(60 \pm 10 \%)$, and a light/dark (12/12 h) cycle with lights on at 5:00 am. They were allowed free access to food and water throughout the experimental period. The study was performed in compliance with the procedures and policies approved by the Research Ethics Committee of Faculty of Medicine, Suez Canal University and in compliance with the Guide for the Care and Use of Laboratory Animal (Council, 2010).

\section{Drugs and chemicals}

Monosodium glutamate (MSG) (C5H9NO4.Na) with purity $99 \%$ was obtained from ALPHA CHEMICA (Mumbai, India). All other high reagent grade chemicals and diagnostic kits were obtained from Sigma-Aldrich (St. Louis, MO, USA). Using specific commercially available kits, lipid peroxidation measured as malondialdehyde (MDA), superoxide dismutase (SOD) activity, catalase (CAT) activity, glutathione (GSH) and glutathione peroxidase (GPx) were measured. Propolis was collected from honeybee hives at an Egyptian farm after freezing. It was ground and 10 grams of it was added to $100 \mathrm{~mL}$ sterile distilled water. The mixture was boiled for one hour with frequent shaking, left to cool, filtered through gauze to recovered the clear working solution (Sforcin and Bankova, 2011).

\section{Animal treatment schedule}

Rats were divided randomly into four equal groups (12 rats/group) and treated as follows:

(i) Control (Gp I) served as control and received $1 \mathrm{ml}$ distilled water;

(ii) Propolis (PP)- (Gp II) was treated orally with propolis $(90 \mathrm{mg} / \mathrm{kg} \mathrm{bw}$ ) (Sartori et al., 2009) dissolved in distilled water once daily;

(iii) MSG (Gp III) was treated orally with MSG (97 $\mathrm{mg} / \mathrm{kg}$ bw, it is prepared in water at $0.64 \mathrm{~g} / \mathrm{L}$ ) (Collison et al., 2009) once daily;

(iv) PP-MSG (Gp IV) was co-treated with propolis $(90 \mathrm{mg} / \mathrm{kg} \mathrm{bw})+$ MSG $(97 \mathrm{mg} / \mathrm{kg}$ bw, it is prepared in water at $0.64 \mathrm{~g} / \mathrm{L}$ ).

All materials were dissolved in distilled water and given once daily for 6 weeks.

One day after the end of the experiment, rats were sacrificed under anesthesia and blood samples were collected for biochemical liver parameters. Liver tissues were harvested for histopathological and histochemical examinations with determination of oxidative markers.

\section{Sampling and investigations}

One day after the end of the experiment, the animals were weighted then morning blood samples from overnight fasting rats were collected from orbital venous plexuses under light diethyl ether anesthesia before sacrifice by cervical dislocation. Serum was recovered from clotted blood by centrifugation at $1000 \mathrm{xg}$ for 10 min at $4{ }^{\circ} \mathrm{C}$ and aliquot was frozen at $-80{ }^{\circ} \mathrm{C}$ till usage. The liver was rapidly dissected out, weighed and prepared for homogenization and histological assessment.

Serum alanine aminotransferase (ALT) and aspartate aminotransferase (AST) were determined in U/L by the method of Reitman and Frankel, (1957). Serum alkaline phosphatase (ALP) was determined according to Bessey et al. (1946). Albumin (g/dL) was determined by the method of Pinnell and Northam, (1978). Total bilirubin level in $\mathrm{mg} / \mathrm{dL}$ were measured based on the method of Perry et al. (1986).

\section{Hepatic homogenate preparation}

One gram of hepatic tissues was homogenized in $9 \mathrm{~mL}$ ice cold phosphate-buffered saline ( $\mathrm{pH} 7.5)$, centrifuged for 15 minutes at $3000 \mathrm{rpm}$ and $4{ }^{\circ} \mathrm{C}$, and, the clear supernatant was stored in aliquots $-80{ }^{\circ} \mathrm{C}$ for further utilization (Fernandez-Botran et al., 2002). Relative body weight (RBW) was calculated as: (final body weight / initial body weight) x 100 and, relative 
liver weight (RLW) was calculated as: (liver weight / final body weight) $\mathrm{x} 100$.

Hepatic MDA and antioxidant enzyme activities estimation:

Hepatic homogenate level of MDA was estimated as thiobarbituric acid reactive substance according to Kei technique (1978). Hepatic homogenate activity of SOD was estimated according to Masayasu and Hiroshi, (1979) technique. The method of Aebi, (1984) was used to determine the hepatic catalase (CAT) activity in tissue homogenates. GSH level was estimated according to Beutler, (1963) technique. Hepatic level of glutathione peroxidase (GPx) was estimated according to Lawrence and Burk, (1976) technique. These are the biochemical bases for the utilized commercial assay kits.

\section{Histopathological examination}

The liver of each rat was carefully dissected out and fixed in $10 \%$ buffered neutral formalin. The fixed liver specimens were routinely dehydrated by graded series of alcohol, cleared in xylol and finally embedded in paraffin. Paraffin blocks were serially sectioned at 4 um thickness and stained with haematoxylin and eosin stains (H\&E) (Bancroft and Gamble, 2008). The gathered sections were collected on glass slides, and succumbed to histopathological examination using the electric light microscope Olympus BH2 (Tokyo, Japan). Masson's trichrome and periodic acid Schiff (PAS) reactions were examined.

\section{Statistical analysis}

All results data were presented as means \pm standard deviation of the means (SD). One-way analysis of variance (ANOVA) was used to compare between animal groups for all the parameters. Difference was considered significant when $\mathrm{p}<0.05$. Statistical analysis was done using SPSS software, version 22 for windows (SPSS, Inc., Chicago, IL, USA).

\section{Results}

Effect of Monosodium glutamate (MSG), propolis (PP) and their combination on body and liver weights

Table 1 shows that after six weeks study period with matched initial body weight, both final and relative body weights (RBW) were significantly increased in GpIII (the group administered MSG) compared to GpI and GpII (control group, and the group given propolis respectively), $(p<0.05)$. After administration of propolis with MSG in GpIV, both final and RBW significantly decreased compared to GpIII. Liver weight and relative liver weight (RLW) were significantly increased in GpIII compared to GpI and GpII $(\mathrm{p}<0.05)$. Propolis significantly decreased liver weight and RLW in GpIV compared to GpIII $(\mathrm{p}<0.05)$. (Table 1)

Effect of Monosodium glutamate (MSG) , propolis (PP) and their combination on liver function parameters

MSG administration in GPIII significantly increased ALT, AST, ALP and bilirubin in parallel with significantly decreased albumin compared to $\mathrm{GpI}$ and GpII $(\mathrm{p}<0.05)$. In group GpIV (PP+MSG), all measured hepatic function parameters were improved significantly compared to GpIII. (Table 2)

Effect of Monosodium glutamate (MSG), propolis (PP) and their combination on liver oxidative markers

Table 3 showed that the antioxidant markers (CAT, SOD,GPx and GSH) levels significantly decreased in GpIII compared to GpI and GpII, while MDA significantly increased compared to those groups $(p<0.05)$. After administration of propolis with MSG in GpIV, the levels of these markers significantly improved compared to MSG group (GpIII) $(\mathrm{p}<0.05)$.

Histopathological and histochemical results

The rats' livers in the different group were examined macroscopically and showed pallor in color, obvious signs of edema and congestion with lack of liver borders. With the cutting of liver tissue, edema and congestion were present.

1. The Light microscope observation

Liver examination of control group using the light microscopic (GpI) and propolis-group (GpII) revealed almost the same histological picture. Hematoxylin \& Eosin stained liver sections of the control group (Gp I, II) showed the normal architecture of the classic hepatic lobules. The hepatocytes form cords radiating from the central veins and separated by radially arranged blood sinusoids. The hepatocytes have round vesicular nuclei and some of them appeared binucleated with no evidence of injury (Fig 1A, B). Sections of MSG-group (GpIII) showed evidence of hepatocytes cell injury: hydropic degeneration, congested sinusoidal vessels and bi-nucleation (Fig 1C). Liver sections of propolis - MSG group (GpIV) showed improvement in the microscopic features of the hepatic architecture, which were almost similar to those of the control group. Sections of propolis - MSG group showed only mild hydropic degeneration (Fig 1D).

2. Histochemical examination:

a. Periodic Acid Schiff's (PAS) observation:

Glycogen content was assessed by periodic acid schiff's (PAS). Examination of the control liver sections (GpI and GpII) stained with PAS showed mucopolysaccharide granules in the cytoplasm of hepatocytes with cytoplasmic reaction with glycogen was seen in hepatocyte (Fig 2A,B).Those in GpIII administered with monosodium glutamate, exhibited increase in the overall amount of PAS positive substance in hepatocyte (Fig 2C). Nevertheless, the rats livers co-treated with monosodium glutamate and propolis with (GpIV) exhibited a mild decrease in cytoplasmic reaction with glycogen in hepatocyte. However, they did not come back to the lower level 
appeared in the normal control group

(Fig 2D).

b. Collagen content

Masson's trichrome stained liver sections of the control group exhibited a collagen with normal distribution, which presented few amount of collagen fibers around the central vein with no fibrous expansion was seen
(Fig 3A,B). However, in GpIII treated with monosodium glutamate, mild fibrous expansion of portal tract (Fig 3C). In GpIV, the liver of rats treated with propolis and MSG, there was an amelioration in the deposition of collagen with no fibrous expansion was seen (Fig 3D).

Table 1: ANOVA one-way statistical analysis of the effects of monosodium glutamate (MSG), propolis, and their combination, on body weight gain, liver weights of rats groups, after six weeks of treatment. $(\mathrm{N}=48)$

\begin{tabular}{|l|l|l|l|l|}
\hline Parameters & GpI (Control) & GpII (PP) & GpIII (MSG) & GpIV (PP+MSG) \\
\hline Initial bodyweight(g) & $189.20 \pm 5.14$ & $188.42 \pm 6.8$ & $191.3 \pm 8.18$ & $190.3 \pm 7.4$ \\
\hline Final bodyweight (g) & $204.8 \pm 10.32$ & $205.22 \pm 9.66$ & $228.38 \pm 12.20^{\text {ab }}$ & $210.6 \pm 5.56^{\mathrm{c}}$ \\
\hline RBW & 108.25 & 108.91 & $119.38^{\mathrm{ab}}$ & $110.66^{\mathrm{c}}$ \\
\hline Liver weight (g) & $8.68 \pm 0.32$ & $8.84 \pm 0.48$ & $17.44 \pm 0.52^{\mathrm{ab}}$ & $9.26 \pm 0.36^{\mathrm{c}}$ \\
\hline RLW & 4.24 & 4.31 & $7.64^{\mathrm{ab}}$ & $4.40^{\mathrm{c}}$ \\
\hline
\end{tabular}

Data are mean \pm standard deviation. GpI: control, GpII: Propolis, GpIII: Monosodium glutamate, GpIV: Propolis+ Monosodium glutamate, RBW: Relative body weight, RLW: Relative liver weight. Relative body weight $=($ final body weight / initial body weight) $x$ 100, Relative liver weight $=($ liver weight / final body weight) $x$ 100, a: compared to the control (GpI) group, b: compared to Propolis (GpII) group, c: compared to Monosodium glutamate (GpIII) group -significant at $p<0.05$

Table 2: ANOVA one-way statistical analysis of the effects of monosodium glutamate (MSG), propolis, and their combination, on rats liver functions after six weeks of treatment. $(\mathrm{N}=48)$

\begin{tabular}{|l|l|l|l|l|}
\hline Parameters & GpI (Control) & GpII (PP) & GpIII (MSG) & GpIV (PP+MSG) \\
\hline ALT (U/L) & $26.32 \pm 3.22$ & $28.76 \pm 4.36$ & $112.22 \pm 6.48^{\mathrm{ab}}$ & $32.34 \pm 4.44^{\mathrm{c}}$ \\
\hline AST(U/L) & $32.80 \pm 5.18$ & $31.66 \pm 4.58$ & $110.36 \pm 4.66^{\mathrm{ab}}$ & $38.76 \pm 4.24^{\mathrm{c}}$ \\
\hline ALP(U/L) & $154.42 \pm 7.50$ & $156.25 \pm 8.88$ & $210.48 \pm 7.66^{\mathrm{ab}}$ & $160.42 \pm 8.38^{\mathrm{c}}$ \\
\hline Albumin(g/dl) & $4.38 \pm 0.44$ & $4.44 \pm 0.5$ & $2.12 \pm 0.48^{\mathrm{ab}}$ & $3.93 \pm 0.16^{\mathrm{c}}$ \\
\hline Bilirubin(mg/dl) & $0.27 \pm 0.06$ & $0.28 \pm 0.02$ & $0.86 \pm 0.12^{\mathrm{ab}}$ & $0.30 \pm 0.04^{\mathrm{c}}$ \\
\hline
\end{tabular}

Data are mean \pm standard deviation. GpI: control, GpII: Propolis, GpIII: Monosodium glutamate, GpIV: Propolis+ Monosodium glutamate, AST: Aspartate transaminase, ALT: Alanine transaminase; ALP: Alkaline phosphatase, a: compared to the control (GpI) group, b: compared to Propolis (GpII) group, c: compared to Monosodium glutamate (GpIII) group, -significant at $p<0.05$

Table 3: ANOVA one-way statistical analysis of the effects of monosodium glutamate (MSG), propolis, and their combination, on liver oxidative markers of rats. $(\mathrm{N}=48)$

\begin{tabular}{|l|l|l|l|l|}
\hline Parameters & GpI (Control) & GpII (PP) & GpIII (MSG) & GpIV (PP+MSG) \\
\hline MDA (mmol/g tissue) & $48.38 \pm 4.46$ & $47.83 \pm 4.14$ & $87.60 \pm 4.62^{\mathrm{ab}}$ & $50.22 \pm 4.28^{\mathrm{c}}$ \\
\hline SOD (U/g tissue) & $288.40 \pm 5.52$ & $291.22 \pm 4.26$ & $220.32 \pm 5.88^{\mathrm{ab}}$ & $285.64 \pm 4.52^{\mathrm{c}}$ \\
\hline CAT (U/g tissue) & $333.58 \pm 18.44$ & $340.24 \pm 20.64$ & $222.34 \pm 12.12^{\mathrm{ab}}$ & $330.66 \pm 18.12^{\mathrm{c}}$ \\
\hline GSH (mmol/g tissue) & $6.88 \pm 0.48$ & $6.90 \pm 0.38$ & $4.16 \pm 0.18^{\mathrm{ab}}$ & $6.78 \pm 0.44^{\mathrm{c}}$ \\
\hline GPx (mmol/g tissue) & $2.66 \pm 0.57$ & $2.78 \pm 0.44$ & $1.42 \pm 0.29^{\mathrm{ab}}$ & $2.48 \pm 0.46^{\mathrm{c}}$ \\
\hline
\end{tabular}

Data are mean \pm standard deviation. GpI: control, GpII: Propolis, GpIII: Monosodium glutamate, GpIV: Propolis+ Monosodium glutamate, CAT: Catalase, SOD: Superoxide dismutase; GSH: Glutathione; GPx: Glutathione peroxidase ; MDA: Malondialdehyde, a: compared to the control (GpI) group, b: compared to Propolis (GpII) group, c: compared to Monosodium glutamate (GpIII) group, significant at $p<0.05$ 

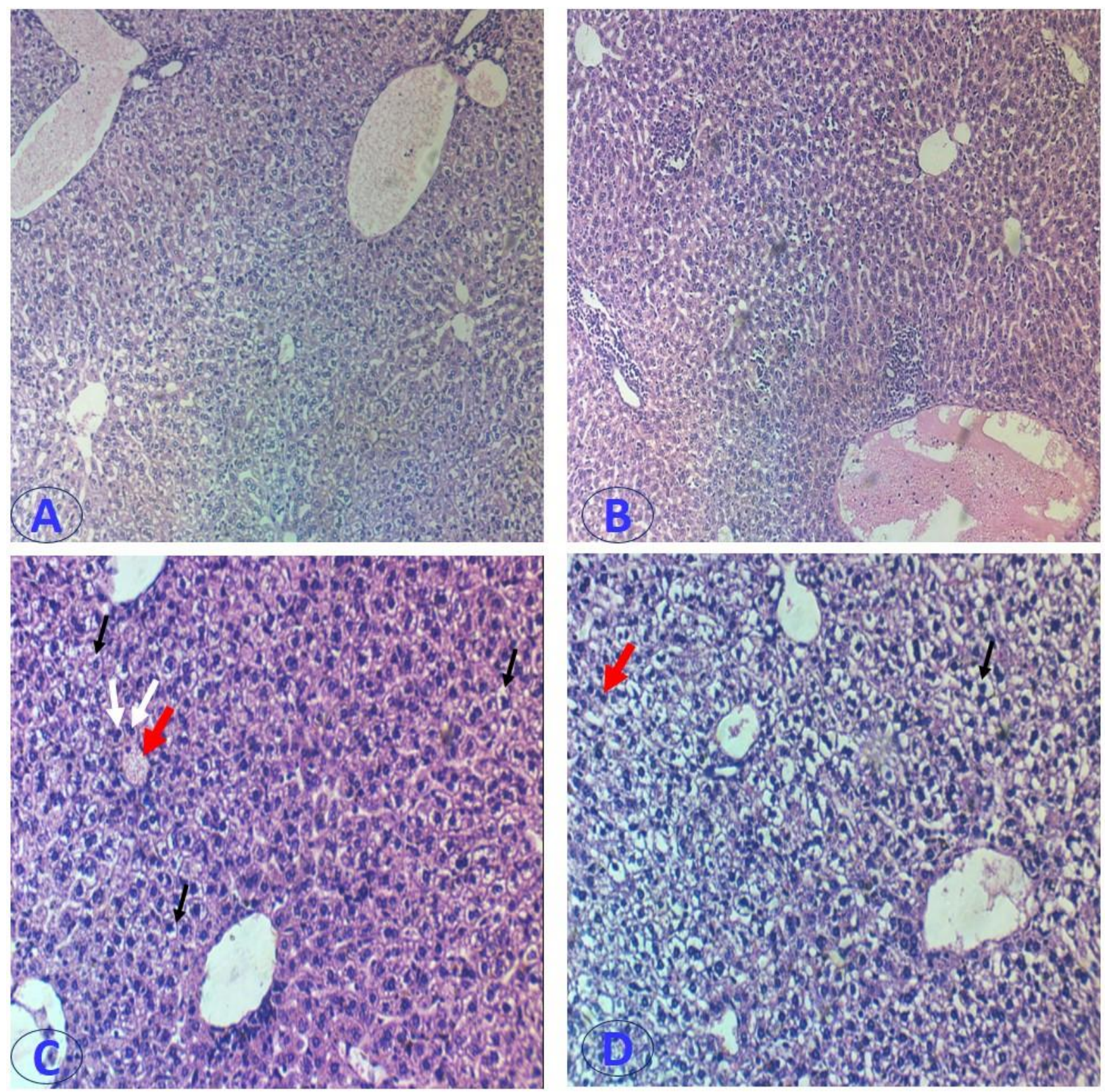

Fig. 1: Photomicrograph of liver sections stained with Hematoxylin \& Eosin from the different groups under the study. (A and B) The control group (Gp I, GpII) showed the normal architecture of the classic hepatic lobules. The hepatocytes form cords radiating from the central veins and separated by radially arranged blood sinusoids. The hepatocytes have round vesicular nuclei and some of them appeared binucleated with no evidence of injury (H\&E, 10x). (C) Sections of MSGgroup (GpIII) showed evidence of hepatocytes cell injury: hydropic degeneration (Black arrows), congested sinusoidal vessels (Red arrow), and bi-nucleation (White arrows) (H\&E, 40x). (D) Liver sections of propolis - MSG group (GpIV) showed improvement in the microscopic features of the hepatic architecture, which were almost similar to those of the control group. Sections of propolis - MSG group showed only mild hydropic degeneration (Black arrows), and binucleation (Red arrow) (H\&E, 40x). 

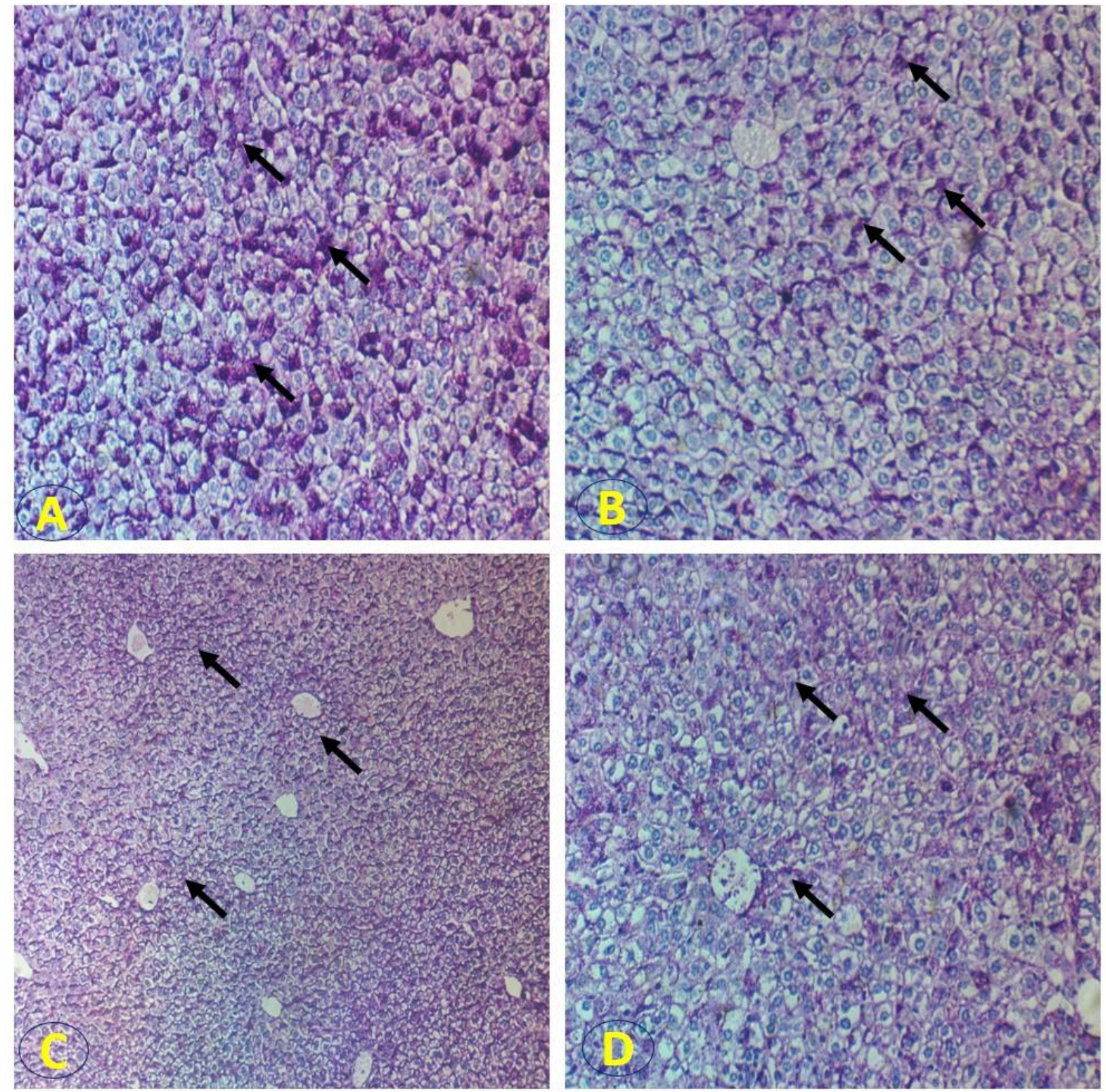

Fig. 2: Light photomicrograph of liver sections stained with periodic acid schiff's (PAS) from the different groups under the study. (A and B) Transverse hepatic section from control rat (GpI, GpII) depicting cytoplasmic reaction with glycogen in hepatocyte (Black arrows) (PAS, 40x). (C) GpIII treated with monosodium glutamate, presented increase in the overall amount of PAS positive substance in hepatocyte (Black arrows) (PAS, 10x). (D) Livers treated with propolis with monosodium glutamate (GpIV) depicted a mild decrease in cytoplasmic reaction with glycogen in hepatocyte (Black arrows) (PAS, 40x). 

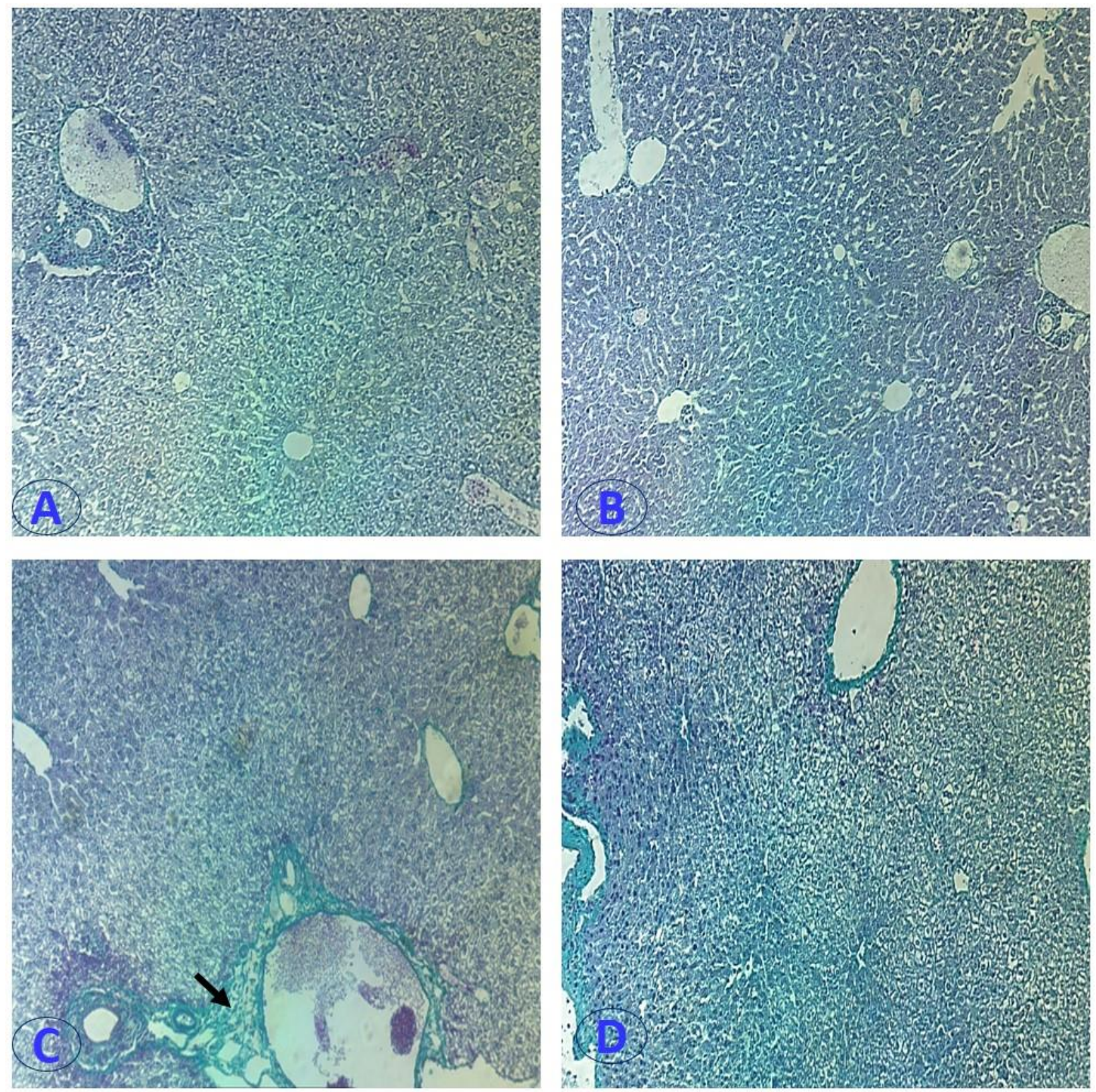

Fig. 3: Light photomicrograph of liver sections stained with Masson's trichrome stain from the different groups under the study. (A and B) Transverse liver section of control groups, presenting collagen with normal distribution, with normal central vein (CV) (Masson's trichrome, 10x). (C) GpIII treated with monosodium glutamate, mild fibrous expansion of portal tract (Black arrow) is seen (Masson's trichrome, 10x). (D) GpIV, the liver of rats treated with propolis and monosodium glutamate, there was an amelioration in the deposition of collagen with no fibrous expansion was seen (Masson's trichrome, 10x). 


\section{Discussion}

Researches reporting the evidence of the toxic and harmful effects of MSG have brought the expanding enthusiasm up in MSG allow as flavor enhancer. In spite of the fact that MSG have role in the appetite enhancing, studies demonstrated that it has a harmful effects on human and experimental animals (Gobatto et al., 2002). Its use has been proved to affect the metabolic processes causing oxidative stress injuries to the tissues (Sant'Diniz et al., 2005) which might be responsible for the pathophysiology of numerous diseases as endothelial damages, diabetes and cancer (Mallick, 2007). In the current study, the biochemical, histopathological and histochemical examinations of MSG- induced liver toxicity were assessed and its prevention by propolis administration.

All the animals included in the study, survived well throughout the experiment. In the current study, the effects of monosodium glutamate evaluated after a period of six weeks in adult rats showed a statistically significant increase in the mean final and relative body weight of rats. This finding is in agreement with Seiva et al. (2012) who reported that MSG-treated rats had increased body weight gain. Nourishment utilization was significantly increased in MSG-treated animals.

Moreover, body weight gain has been significantly reduced in rats treated with MSG after administration of propolis as a co-treatment as propolis has an inclination in decreasing rat's food intake. Peluso, (2006) stated that flavonoids have been described as modulators of lipid homeostasis in the adipose tissue and liver, through the inhibition of phosphodiesterases. Body weight gain is attributed to hyperphagia, which is firmly connected to the impairment in metabolic process in the body, yet it has additionally observed to be related to dyslipidemia, hyperleptinemia and insulin resistance/glucose tolerance (Sant'Diniz et al., 2005). In the current study, appetite control center had most likely been compromised in the rats treated with MSG. Adipocytes secrete a protein called Leptin. After binding Leptin to its hypothalamic receptor, it is fundamentally responsible for induction of satiety. Previous reports had depicted that hyperphagia caused in rats treated with MSG is mainly attributed to the toxicity induced by MSG which induced insufficient binding of leptin to its receptors (Afifi and Abbas, 2011), accordingly elevating levels of leptin in serum. This is in agreement with Rani et al. (2013) who reported that the rats at the end of the experiment of MSG exposure appeared more obese than the control animals.

The results in the current study showed that serum levels of ALT, AST and ALP were significantly increased in-group of rats treated with MSG denoting liver injuries. It is believed that the elevation and induction of these enzymes activities could be attributed to the damage in liver caused by MSG administration with hepatocytes spillage of these enzymes. Propolis use as co-treatment significantly ameliorates and restores the levels of these enzymes. The reversal of increased serum enzymes in MSG induced liver damage by propolis may be due to the prevention of the leakage of intracellular enzymes by its membrane stabilizing activity. This is in agreement with the commonly accepted view that serum levels of transaminases return to normal with the healing of hepatic parenchyma and the regeneration of hepatocytes (Wagh, 2013, Bankova, 2005).

Furthurmore, Vieira et al. 2011 reported that the liver and its functions are propably protected and ameliorated with the administartion of propolis. Yousef et al. (2010) and Farombi and Onyema, (2006) have identified and confirmed the finding that MSG induced liver damage and increased ALP, AST, and ALT enzymes in serum with metabolic derangements.

Interestingly, many researchers have attributed the hepatoprotective effect of propolis directly to stabilization of redox state in the cells (Anjum et al., 2018, El-Guendouz et al., 2017). Oxidative stress reflects an imbalance between the systemic manifestation of reactive oxygen species and a biological system's ability to readily detoxify the reactive intermediates or to repair the resulting damage. Disturbances in the normal redox state of cells can cause toxic effects through the production of peroxides and free radicals that damage all components of the cell, including proteins, lipids, and DNA, as occurs with MSG toxicity (AL-Mosaibih, 2013) .

These finding are in agreement with Diniz et al. (2004) , Tawfik and Al-Badr, (2012) and AL-Mosaibih, (2013) who stated that animals treated with MSG orally at a dose of $0.6 \mathrm{mg} / \mathrm{g}$ for 10 days induced hepatic damage through oxidative stress, which caused lipid peroxidation, deceased levels of antioxidant enzymes; superoxide dismutase and catalase with diminished glutathionetransferase activity. In the same context, Valko et al. (2007) reported that oxidative stress could be induced and displayed in the cardiac tissue after administration of MSG at a dose of $4,8 \mathrm{mg} / \mathrm{g}$ body weight with modification of CAT and SOD levels

The current study showed that the hepatic tissues of rats treated with MSG exhibited remarkable histopathological derangements. Comparable findings have been mentioned in other studies (Inkielewicz and Krechniak, 2003, Ayman et al., 2013, Kumbhare et al., 2015).

Eweka et al. (2011) and Ayman et al. (2013) revealed that liver central vein has been dilated in group of rats treated with MSG in comparison with hepatic section of control groups. This is in a good agreement with the data provided in the current experiment that MSG administration in rats caused hydropic degeneration, congested sinusoidal vessels in the toxic group compared to the hepatic tissues of control groups. These hisopathological changes are in the same line with previous researchers (Ortiz et al., 2006) who reported that the liver showed steatosis and necrosis. All of these 
data could be explained by the excitotoxic role of the glutamate.

These findings are similar to the results of Onyema et al. (2006) and Ortiz et al. (2006) who revealed that some areas of hepatic apoptosis and necrosis are found in hepatic tissues of MSG-treated rats. Conversely , Egbuonu et al. (2009) revealed that hepatocytes degeneration, biliary proliferation and peribiliary fibrosis are induced by MSG-treated rats. The current study revealed hepatic fibrosis, which can be attributed to the diminished production of glutathione peroxidase and the increased generation of malondialdehyde (MDA) in the hepatocytes. This is in concurrence with Yaqub et al. (2008) who reported that oxidative stress assumes a significant role in the emergence of hepatic degeneration and fibrosis.

The treatment with propolis significantly alleviated the MSG derangements in functions of the liver. It appears to fulfill the structural integrity of the liver as evident in the increase in the antioxidants parameters (CAT, SOD, GPx, and GSH) and a reduction in MDA level. Additionally, it has ameliorated the hepatic histopathological changes. This finding affirmed by (Peña, 2008, Anjum et al., 2018) who mentioned that the histopathological changes in the diseased organs are relieved with propolis treatment approximately to control groups.

Moreover, these findings indicated that the levels of hepatic antioxidant enzymes (SOD and CAT) and content (GSH) are down regulated by MSG administration. These observations come in the same context with Seiva et al. (2012) who reported that the antioxidant enzymes levels decreased with MSG administration. However, these enzymes restored approximately to the normal control level with the administration of natural antioxidants.

Propolis utilization has considerable impact on human body systems and is utilized for different reasons. Recently , it is utilized as an antioxidant, antiinflammatory, antifungal, anesthetic, antiviral , antibacterial (Omar et al., 2017), anticancer, antitumoural , antiprotozoal (Kuropatnicki et al., 2013, Abdulrhman et al., 2012, Sforcin, 2016) anti-hepatotoxic, anticarcinogenic , antihypertensive with cytotoxic properties, etc. (Toreti et al., 2013).

Many researchers (Andrade et al., 2008, Peña, 2008) depicted that propolis works as a hepatoprotective substance. It elevates the level of glutathione while declining oxidized glutathione level and lipid peroxidation. Thus, antioxidant activity of the liver is enhanced by propolis intake against various hepatotoxic agents. Previous studies also reported that, propolis has ameliorative role against the hepatic and renal damage caused by the oxidative stress damage (Wagh, 2013). Propolis exhibited amelioration of hepatic toxicity and liver injuries induced by paracetamol, allyl alcohol, and CCL4 in rats (Wagh, 2013). Bankova, (2005) reported in his research that diterpenic acids as well as isolated phenolic components of propolis, exhibit hepatoprotective peculiarity.

Kuropatnicki et al. (2013) showed that propolis consists of more than 180 various kinds of chemicals . In general, propolis contains polyphenol (flavonoids, phenolic acids and esters) (Król et al., 2013, Kumar et al., 2008), ketones and, phenolic aldehydes etc. (Elnakady et al., 2017). The distribution of these materials is as follows: resins and vegetable balsam 50\%, Bee wax $30 \%$, pollen $5 \%$, essential and aromatic oils $10 \%$, as well as some other substances and organic compounds (Abdulkhani et al., 2017, Kuropatnicki et al., 2013, Martinotti and Ranzato, 2015, Rufatto et al., 2017, Sabir, 2017).

Recent researchers reported that propolis has a cyto-protective role due to its antioxidant property, which attributed to its ingredients galangin and pinocembrin (Al-Hariri, 2011, El-Guendouz et al., 2017, MACHADO et al., 2017, Martinotti and Ranzato, 2015). The propolis antioxidant property can be attributed to its ingredients from phenol compounds, which give hydrogen ions to free radicals preventing oxidation reactions in the cells, as well as protecting against oxidation and poisoning associated with food storage. Propolis had the ability to get rid of free radicals, which are the fundamental cause of lipids, proteins and nucleic acids oxidation (Chandna et al., 2014). It is also reported by Zabaiou et al. 2017 that human red blood cells are protected by propolis due to its counteracting property against lipid peroxidation, which confirmed its antioxidant property.

\section{Conclusion}

Propolis effectively enhances the improvement and amelioration of the nutritional characters and the damage induced by MSG administration. Furthermore, propolis mitigated the hepatic toxic manifestations induced by MSG in rats. These consequences are attributed to the antioxidant characteristics of propolis. The study encourages a high propolis intake for those who exposed to MSG, as it has great beneficial impacts against many toxic substances and metabolic disorders.

\section{Conflict of Interest}

The authors declare that we have no conflict of interest.

\section{References}

Abdulkhani, A., Hosseinzadeh, J., Ashori, A. \& Esmaeeli, H. 2017. Evaluation Of The Antibacterial Activity Of Cellulose Nanofibers/Polylactic Acid Composites Coated With Ethanolic Extract Of Propolis. Polymer Composites, 38, 13-19.

Abdulrhman, M., Samir Elbarbary, N., Ahmed Amin, D. \& Saeid Ebrahim, R. 2012. Honey And A Mixture Of Honey, Beeswax, And Olive OilPropolis Extract In Treatment Of Chemotherapy-Induced Oral Mucositis: A Randomized Controlled Pilot Study. Pediatric Hematology And Oncology, 29, 285-292.

Aebi, H. 1984. [13] Catalase In Vitro. Methods In Enzymology. Elsevier. 
Afifi, M. \& Abbas, A. 2011. Monosodium Glutamate Versus Diet Induced Obesity In Pregnant Rats And Their Offspring. Acta Physiologica Hungarica, 98, 177-188.

AL-Harbi, M. S., El-Shenawy, N. S. \& AL-Weail, N. O. 2014. Effect Of Monosodium Glutamate On Oxidative Damage In The Male Mice: Modulatory Role Of Vitamin C. Adv. Food Sci.

AL-Hariri, M. T. 2011. Propolis And Its Direct And Indirect Hypoglycemic Effect. Journal of Family And Community Medicine, 18, 152.

AL-Mosaibih, M. A. 2013. Effects Of Monosodium Glutamate And Acrylamide On The Liver Tissue Of Adult Wistar Rats. Life Sci. J, 10, 3542.

Andrade, S. F., DA Silva Filho, A. A., Cunha, W. R., Nanayakkara, N. D. \& Bastos, J. K. 2008. Antileishmanial, Antimalarial And Antimicrobial Activities Of The Extract And Isolated Compounds From Austroplenckia Populnea (Celastraceae). Zeitschrift Für Naturforschung C, 63, 497-502.

Anjum, S. I., Ullah, A., Khan, K. A., Attaullah, M., Khan, H., Ali, H., Bashir, M. A., Tahir, M., Ansari, M. J. \& Ghramh, H. A. 2018. Composition And Functional Properties Of Propolis (Bee Glue): A Review. Saudi Journal Of Biological Sciences.

Ayman, E., Osman, H. E. H. \& Daghestani, M. H. 2013. The Effect Of Vitamin C Administration On Monosodium Glutamate Induced Liver Injury. An Experimental Study. Experimental And Toxicologic Pathology, 65, 513-521.

Bancroft, J. D. \& Gamble, M. 2008. Theory And Practice Of Histological Techniques, Elsevier Health Sciences.

Bankova, V. 2005. Recent Trends And Important Developments In Propolis Research. EvidenceBased Complementary And Alternative Medicine, 2, 29-32.

Bessey, O. A., Lowky, O. \& Brock, M. J. 1946. A Method For The Rapid Determination Of Alkaline Phosphatase With Five Cubic Millimeters Of Serum. Journal Of Biological Chemistry, 164, 321-329.

Beutler, E. 1963. Improved Method For The Determination Of Blood Glutathione. J. Lab. Clin. Med., 61, 882-888.

Bueno-Silva, B., Alencar, S. M., Koo, H., Ikegaki, M., Silva, G. V., Napimoga, M. H. \& Rosalen, P. L. 2013. Anti-Inflammatory And Antimicrobial Evaluation Of Neovestitol And Vestitol Isolated From Brazilian Red Propolis. Journal of Agricultural And Food Chemistry, 61, 45464550.

Chandna, P., Adlakha, V. K., Das, S. \& Singh, S. 2014. Complementary And Alternative Medicine (CAM): A Review Of Propolis In Dentistry. Technology, 4.
Collison, K. S., Maqbool, Z., Saleh, S. M., Inglis, A., Makhoul, N. J., Bakheet, R., AL-Johi, M., ALRabiah, R., Zaidi, M. Z. \& AL-Mohanna, F. A. 2009. Effect Of Dietary Monosodium Glutamate On Trans Fat-Induced Nonalcoholic Fatty Liver Disease. Journal Of Lipid Research, 50, 15211537.

Council, N. R. 2010. Guide For The Care And Use Of Laboratory Animals, National Academies Press.

Diniz, Y. S., Fernandes, A. A., Campos, K. E., Mani, F., Ribas, B. O. \& Novelli, E. L. 2004. Toxicity Of Hypercaloric Diet And Monosodium Glutamate: Oxidative Stress And Metabolic Shifting In Hepatic Tissue. Food And Chemical Toxicology, 42, 313-319.

Dixit, S. G., Rani, P., Anand, A., Khatri, K., Chauhan, R. \& Bharihoke, V. 2014. To Study The Effect Of Monosodium Glutamate On Histomorphometry Of Cortex Of Kidney In Adult Albino Rats. Renal Failure, 36, 266-270.

Egbuonu, A., Obidoa, O., Ezeokonkwo, C. \& Ejikeme, P. 2009. Hepatotoxic Effects Of Low Dose Oral Administration Of Monosodium Glutamate In Male Albino Rats. African Journal of Biotechnology, 8.

EL-Guendouz, S., AL-Waili, N., Aazza, S., Elamine, Y., Zizi, S., AL-Waili, T., AL-Waili, A. \& Lyoussi, B. 2017. Antioxidant And Diuretic Activity Of Co-Administration Of Capparis Spinosa Honey And Propolis In Comparison To Furosemide. Asian Pacific Journal Of Tropical Medicine, 10, 974-980.

Elnakady, Y. A., Rushdi, A. I., Franke, R., Abutaha, N., Ebaid, H., Baabbad, M., Omar, M. O. \& AL Ghamdi, A. A. 2017. Characteristics, Chemical Compositions And Biological Activities of Propolis From Al-Bahah, Saudi Arabia. Scientific Reports, 7, 41453.

Eweka, A., Igbigbi, P. \& Ucheya, R. 2011. Histochemical Studies Of The Effects Of Monosodium Glutamate On The Liver Of Adult Wistar Rats. Annals of Medical And Health Sciences Research, 1, 21-30.

Eweka, A. \& Om'iniabohs, F. 2011. Histological Studies Of The Effects Of Monosodium Glutamate On The Ovaries Of Adult Wistar Rats. Annals of Medical And Health Sciences Research, 1, 3744.

Farombi, E. \& Onyema, O. 2006. Monosodium Glutamate-Induced Oxidative Damage And Genotoxicity In The Rat: Modulatory Role Of Vitamin C, Vitamin E And Quercetin. Human \& Experimental Toxicology, 25, 251-259.

Fernandez-Botran, R., Gorantla, V., Sun, X., Ren, X., Perez-Abadia, G., Crespo, F. A., Oliver, R., Orhun, H. I., Quan, E. E. \& Maldonado, C. 2002. Targeting Of GlycosaminoglycanCytokine Interactions As A Novel Therapeutic 
Approach In Allotransplantation1.

Transplantation, 74, 623-629.

Gobatto, C., Mello, M., Souza, C. \& Ribeiro, I. 2002. The Monosodium Glutamate (Msg) Obese Rat As A Model For The Study Of Exercise In Obesity. Research Communications In Molecular Pathology And Pharmacology, 111, 89-101.

Hamza, R. Z. \& Al-Harbi, M. S. 2014. Monosodium Glutamate Induced Testicular Toxicity And The Possible Ameliorative Role Of Vitamin E Or Selenium In Male Rats. Toxicology Reports, 1, 1037-1045.

Inkielewicz, I. \& Krechniak, J. 2003. Fluoride Content In Soft Tissues And Urine Of Rats Exposed To Sodium Fluoride In Drinking Water. Fluoride, 36, 263-266.

Kei, S. 1978. Serum Lipid Peroxide In Cerebrovascular Disorders Determined By A New Colorimetric Method. Clinica Chimica Acta, 90, 37-43.

Król, W., Bankova, V., Sforcin, J. M., Szliszka, E., Czuba, Z. \& Kuropatnicki, A. K. 2013. Propolis: Properties, Application, And Its Potential. Evidence-Based Complementary And Alternative Medicine, 2013.

Kumar, N., Kk, M. A., Dang, R. \& Husain, A. 2008. Antioxidant And Antimicrobial Activity Of Propolis From Tamil Nadu Zone. Journal of Medicinal Plants Research, 2, 361-364.

Kumbhare, V., Gajbe, U., Singh, B. R., Reddy, A. K. \& Shukla, S. 2015. Histological \& Histochmical Changes In Liver Of Adult Rats Treated With Monosodium Glutamate: A Light Microscopic Study. Wjpps, 4, 898-911.

Kuropatnicki, A. K., Szliszka, E. \& Krol, W. 2013. Historical Aspects Of Propolis Research In Modern Times. Evidence-Based Complementary And Alternative Medicine, 2013.

Lawrence, R. A. \& Burk, R. F. 1976. Glutathione Peroxidase Activity In Selenium-Deficient Rat Liver. Biochemical And Biophysical Research Communications, 71, 952-958.

Machado, B., Pulcino, T. N., Silva, A. L., Tadeu, D., Melo, R. G. S. \& Mendonça, I. G. 2017. Propolis As An Alternative In Prevention And Control Of Dental Cavity. Immunity, 19, 24.

Mallick, H. 2007. Understanding Safety Of Glutamate In Food And Brain. Indian Journal Of Physiology And Pharmacology, 51, 216.

Martinotti, S. \& Ranzato, E. 2015. Propolis: A New Frontier For Wound Healing? Burns \& Trauma, $3,9$.

Masayasu, M. \& Hiroshi, Y. 1979. A Simplified Assay Method Of Superoxide Dismutase Activity For Clinical Use. Clinica Chimica Acta, 92, 337342.

Omar, R., Igoli, J. O., Zhang, T., Gray, A. I., Ebiloma, G. U., Clements, C. J., Fearnley, J., Ebel, R. E., Paget, T. \& De Koning, H. P. 2017. The
Chemical Characterization Of Nigerian Propolis Samples And Their Activity Against Trypanosoma Brucei. Scientific Reports, 7, 923.

Onyema, O. O., Farombi, E. O., Emerole, G. O., Ukoha, A. I. \& Onyeze, G. O. 2006. Effect Of Vitamin E On Monosodium Glutamate Induced Hepatotoxicity And Oxidative Stress In Rats.

Ortiz, G., Bitzer-Quintero, O., Zárate, C. B., RodríguezReynoso, S., Larios-Arceo, F., VelázquezBrizuela, I., Pacheco-Moisés, F. \& RosalesCorral, S. 2006. Monosodium GlutamateInduced Damage In Liver And Kidney: A Morphological And Biochemical Approach. Biomedicine \& Pharmacotherapy, 60, 86-91.

Peluso, M. R. 2006. Flavonoids Attenuate Cardiovascular Disease, Inhibit Phosphodiesterase, And Modulate Lipid Homeostasis In Adipose Tissue And Liver. Experimental Biology And Medicine, 231, 1287-1299.

Peña, R. C. 2008. Propolis Standardization: A Chemical And Biological Review. Cien. Inv. Agr. 35 (1): 17-26. Ciencia E Investigación Agraria, 35, 1120.

Perry, B., Doumas, B., Buffone, G., Glick, M., Ou, C. \& Ryder, K. 1986. Measurement Of Total Bilirubin By Use Of Bilirubin Oxidase. Clinical Chemistry, 32, 329-332.

Pinnell, A. E. \& Northam, B. E. 1978. New Automated Dye-Binding Method For Serum Albumin Determination With Bromcresol Purple. Clinical Chemistry, 24, 80-86.

Rani, P., Khatri, K. \& Chauhan, R. 2013. Monosodium Glutamate Induced Histomorphometric Changes In Thyroid Gland Of Adult Wistar Rat. Journal Of Medical \& Allied Sciences, 3, 67.

Reitman, S. \& Frankel, S. 1957. A Colorimetric Method For The Determination Of Serum Glutamic Oxalacetic And Glutamic Pyruvic Transaminases. American Journal Of Clinical Pathology, 28, 56-63.

Rizk, S. M., Zaki, H. F. \& Mina, M. A. 2014. Propolis Attenuates Doxorubicin-Induced Testicular Toxicity In Rats. Food And Chemical Toxicology, 67, 176-186.

Rufatto, L. C., Dos Santos, D. A., Marinho, F., Henriques, J. A. P., Ely, M. R. \& Moura, S. 2017. Red Propolis: Chemical Composition And Pharmacological Activity. Asian Pacific Journal Of Tropical Biomedicine, 7, 591-598.

Sabir, A. 2017. Prospect Of Using Propolis In Conservative Dentistry And Endodontic Treatment (Basic Research Vs Clinical Application)(Prospek Penggunaan Propolis Dalam Bidang Operative Dentistry Dan Perawatan Endodonti (Penelitian Dasar Vs Aplikasi Klinis)). Dentika Dent. J, 18.

Sakr, S., El-Messedy, F. \& Abdel-Samei, H. 2002. Histopathological And Histochemical Effects Of Gibberellin A3 On The Kidney Of Albino Rats. 
Journal-Egyptian German Society Of Zoology, $38,1-10$.

Sakr, S. A., Okdah, Y. A. \& El-Abd, S. F. 2003. Gibberellin A3 Induced Histological And Histochemical Alterations In The Liver Of Albino Rats. Science Asia, 29, 327-31.

Sant'diniz, Y., Faine, L. A., Galhardi, C. M., Rodrigues, H. G., Ebaid, G. X., Burneiko, R. C., Cicogna, A. C. \& Novelli, E. L. 2005. Monosodium Glutamate In Standard And High-Fiber Diets: Metabolic Syndrome And Oxidative Stress In Rats. Nutrition, 21, 749-755.

Sartori, D., Kawakami, C., Orsatti, C. \& Sforcin, J. 2009. Propolis Effect On Streptozotocin-Induced Diabetic Rats. Journal Of Venomous Animals And Toxins Including Tropical Diseases, 15, 93102.

Seiva, F. R., Chuffa, L. G. A., Braga, C. P., Amorim, J. P. A. \& Fernandes, A. A. H. 2012. Quercetin Ameliorates Glucose And Lipid Metabolism And Improves Antioxidant Status In Postnatally Monosodium Glutamate-Induced Metabolic Alterations. Food And Chemical Toxicology, 50, 3556-3561.

Sforcin, J. M. 2016. Biological Properties And Therapeutic Applications Of Propolis. Phytotherapy Research, 30, 894-905.

Sforcin, J. M. \& Bankova, V. 2011. Propolis: Is There A Potential For The Development Of New Drugs? Journal Of Ethnopharmacology, 133, 253-260.

Tawfik, M. S. \& Al-Badr, N. 2012. Adverse Effects Of Monosodium Glutamate On Liver And Kidney Functions In Adult Rats And Potential Protective Effect Of Vitamins C And E. Food And Nutrition Sciences, 3, 651.

Toreti, V. C., Sato, H. H., Pastore, G. M. \& Park, Y. K. 2013. Recent Progress Of Propolis For Its Biological And Chemical Compositions And Its Botanical

Origin.

Evidence-Based
Complementary And Alternative Medicine, 2013.

Torii, K. 2012. Brain Activation By The Umami Taste Substance Monosodium L-Glutamate Via Gustatory And Visceral Signaling Pathways, And Its Physiological Significance Due To Homeostasis After A Meal. Journal Of Oral Biosciences, 54, 144-150.

Valko, M., Leibfritz, D., Moncol, J., Cronin, M. T., Mazur, M. \& Telser, J. 2007. Free Radicals And Antioxidants In Normal Physiological Functions And Human Disease. The International Journal Of Biochemistry \& Cell Biology, 39, 44-84.

Vieira, E. K., Bona, S., Di Naso, F. C., Porawski, M., Tieppo, J. \& Marroni, N. P. 2011. Quercetin Treatment Ameliorates Systemic Oxidative Stress In Cirrhotic Rats. Isrn Gastroenterology, 2011.

Wagh, V. D. 2013. Propolis: A Wonder Bees Product And Its Pharmacological Potentials. Advances In Pharmacological Sciences, 2013.

Yaqub, H., Abdel Baky, N., Attia, H. A. \& Faddah, L. 2008. Hepatoprotective Effect Of N-Acetyl Cysteine And/Or B-Carotene On Monosodium Glutamate-Induced Toxicity In Rats. Res $J$ Med Med Sci, 3, 206-215.

Yousef, M. I., Omar, S. A., El-Guendi, M. I. \& Abdelmegid, L. A. 2010. Potential Protective Effects Of Quercetin And Curcumin On Paracetamol-Induced Histological Changes, Oxidative Stress, Impaired Liver And Kidney Functions And Haematotoxicity In Rat. Food And Chemical Toxicology, 48, 3246-3261.

Zabaiou, N., Fouache, A., Trousson, A., Baron, S., Zellagui, A., Lahouel, M. \& Lobaccaro, J.-M. A. 2017. Biological Properties Of Propolis Extracts: Something New From An Ancient Product. Chemistry And Physics Of Lipids, 207, 214-222. 
الملخص العزبي

تقييم الفحص النسيج المرضي و النسيج الكيميائي للسمية الكبدية الناتجة عن الغلوتاميت أحادية الصوديوم والتحسين الناتج عن صمغ النحل.

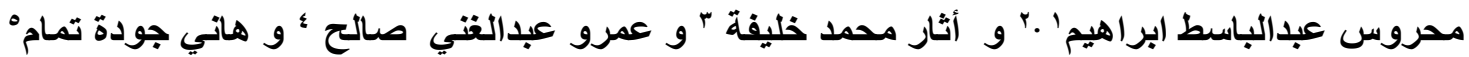

المقدمة: تعد الغلوتاميت أحادية الصوديوم (MSG) مواد شائعة الاستخدام حيث تضاف للأغذية لفتح الشهية وهناك قلق متزايد من أن

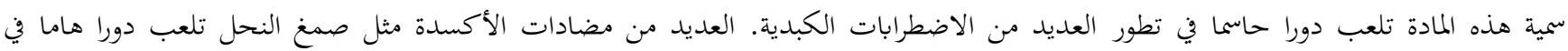
الحماية ضد السمية الكبدية.

هدف الدراسة: الهدف من هذه الدراسة هو التحقق من التأثير الوقائي لصمغ النحل على السمية الكبدية الناجمة عن الغلوتاميت أحادية الصوديوم.

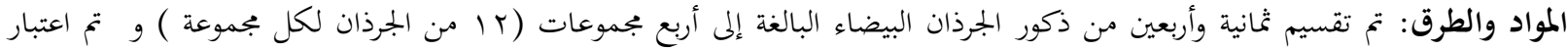

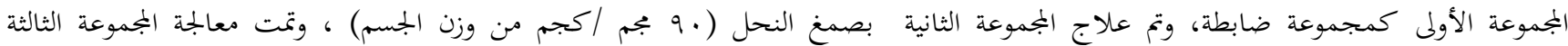

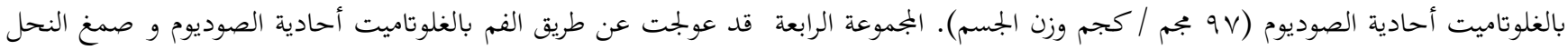

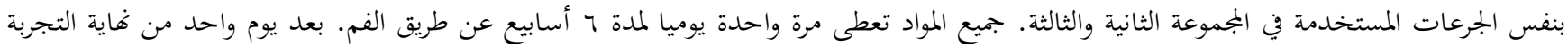

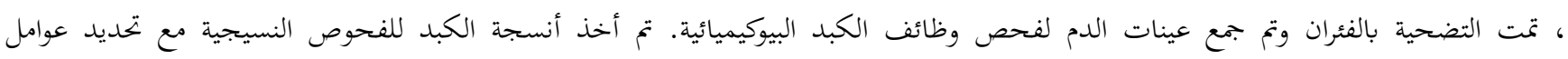
ومضادات الاكسدة. النتائج: أوضحت النتائج أن نشاط الانيمات الكبدية قد زاد بشكل كبير في مصل الدم عند إعطاء الغلوتاميت أحادية الصوديوم بينما

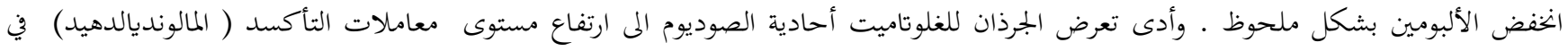

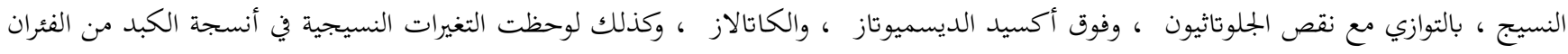

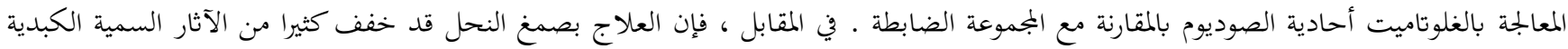
المحدثة من الغلوتاميت أحادية الصوديوم ، كما لوحظ المزيد من التحسينات على التغيرات النسيجية.

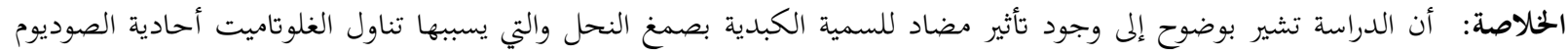

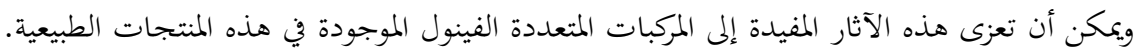

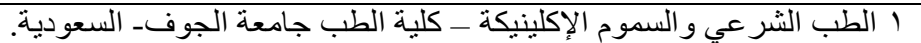

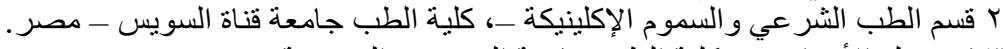

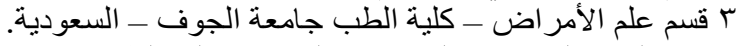

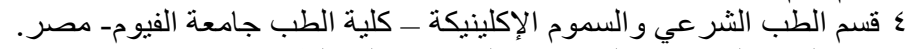

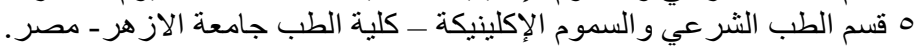

